\title{
Polyfluorinated nitroxides
}

\author{
Xi-Kui Jiang \\ Shanghai Institute of Organic Chemistry, Academia Sinica, \\ 345 Lingling Lu, Shanghai 200032, China
}

\begin{abstract}
Over 140 polyfluorinated nitroxides, mostly new, have been generated by some novel reactions. Many of them are initiated by electrontransfer processes. Mechanistic aspects of these reactions are discussed. ESR spectra of these nitroxides, including the temperature dependence of some $a_{\mathrm{N}}$ and $a_{\mathrm{F}}$ values, and of selective line broadening, have been investigated. Substituent effects on the $a_{N}$ and $a_{F}$ values of some nitroxides have been discussed.
\end{abstract}

\section{INTRODUCTION}

Nitroxides are one of the most studied class of compounds in radical chemistry (ref. 1 ). Although among various types of nitroxides, polyfluoroalkyl nitroxides have also aroused much research interest, only few reactions were used to generate these radicals. The first bis(polyfluoroalkyl) nitroxide $1, i . e ., 1-1 F$, was prepared by the oxidation of the corresponding hydroxylamine in 1965, and this method is still used today (ref. 2 ). A number of alkyl polyfluoroalkyl nitroxides 2 were generated by using spin trapping reactions of 2methyl-2-nitrosopropane, nitrosobenzene or 2-methyl-2-nitrosobutanone-3 and fluorinated radicals derived either from radical addition to fluoroolefins or from the photolysis of polyfluoroalkyl iodides $R_{\mathrm{p}} I$ (ref. 3 ). Many polyfluorinated nitroxides were generated by direct reaction of a fluoroolefin with a nitroso compound, especially with $\mathrm{CF}_{3} \mathrm{NO}$ (ref. 4 ).

Thao et al. have generated over 140 polyfluoro- or perfluoroalkyl nitroxides, including the symmetrical bis(polyfluoroalkyl) nitroxides 1 ( $1-n Y)$, and the alkyl polyfluoroalkyl nitroxides $\underline{2}(\underline{2-n Y-R})$, most of them new compounds (ref. 5-15). Most of these nitroxides were

$$
\begin{array}{lr}
Y-\left(C F_{2}\right)_{n}-N\left(0^{\circ}\right)-\left(C F_{2}\right)_{n}-Y & Y-\left(C F_{2}\right)_{n}-N\left(0^{\circ}\right)-R \\
\underline{1} \text { or } \underline{1-n Y}, e .9 ., \underline{1-2 C l} & \underline{2} \text { or } \underline{2-n Y-R}, e . g,, \underline{2-4 H-t B u} \\
\text { for } n=2, Y=C l . & \text { for } n=4, Y=H, R=t B u .
\end{array}
$$

obtained by using new reactions, and many of these reactions are initiated by electrontransfer (ET) processes (ref. 5,6,9). Mechanistic aspects of these reactions have also been discussed.

ESR spectra of these nitroxides, including the temperature dependence of some a and a values as well as selective line broadening, have been investigated. Structure and substituent effects on the $a_{1}$ and $a_{\text {}}$ values of these nitroxides have been discussed. Correlation analysis of $a_{\text {and }} a_{p}$ with suostituent parameters $\left(\sigma_{p}, \sigma^{*}\right.$, etc. $)$, of nine para-substituted benzoyl $\omega$-H-perfluoro-n-hexyl nitroxides has been studied (ref. 12 ).

Spin trapping experiments have been performed on several other reactions. Our results indicate that (1) $\mathrm{N}$-bromotetrafluorosuccinimide reacts by a radical rather than by an ionic mechanism (ref. 16), (2) bis(poly- or perfluoroalkyl)nitroxides can selectively abstract H-atoms from various hydrocarbon substrates $(R-H)$, and (3) subsequent reactions eventually yield nitroxides of the type $\mathrm{R}_{\mathrm{F}}-\mathrm{N}\left(\mathrm{O}^{\circ}\right)-\mathrm{R}$ or $\underline{2-\mathrm{nY}-\mathrm{R}}$ (ref. 11 ).

\section{SOME NEW REACTIONS FOR GENERATING FLUORINATED NITROXIDES}

In recent years, we have worked out a series of reactions or conditions (eq. 1-13) which yield $R_{i}$ radicals as well as their nitroxides at room temperature or below. Two types of nitroxides are formed, i.e., the symmetrical bis(polyfluoroalkyl) nitroxides $\underline{1}(\underline{1-n Y})$, and alkyl polyfluoroalkyl nitroxides $\underline{2}(\underline{2-n Y-R})$ ( ref. 5-15). In following equations, OP stands for " other products".

$$
\begin{aligned}
\left(\mathrm{R}_{\mathrm{F}} \mathrm{COO}\right)_{2}(\underline{3}) \text {, or } \mathrm{R}_{\mathrm{F}} \mathrm{I}(\underline{4}) \text {, or } \mathrm{R}_{\mathrm{F}} \mathrm{SO}_{2} \mathrm{Br}(\underline{5})+\mathrm{MNO}_{2}(\underline{6}) \\
\longrightarrow \quad \mathrm{R}_{\mathrm{F}}-\mathrm{NO}(\underline{7})+\mathrm{R}_{\mathrm{F}}-\mathrm{N}\left(0^{\circ}\right)-\mathrm{R}_{\mathrm{F}}(\underline{1})+\mathrm{OP}
\end{aligned}
$$




$$
\begin{aligned}
& \underline{3}+\mathrm{RR}^{\prime} \mathrm{CNO}_{2} \mathrm{Na}(\underline{8})-\underline{7}+\underline{\underline{1}}+\mathrm{R}_{\mathrm{F}}-\mathrm{N}\left(0^{\circ}\right)-\mathrm{CRR}^{\prime} \mathrm{NO}_{2}\left(\underline{\left(2-\mathrm{nY}-\mathrm{CRR}^{\prime} \mathrm{NO}_{2}\right)}+\mathrm{OP}\right. \\
& \underline{3}+\mathrm{Me}_{2} \mathrm{C}\left(\mathrm{NO}_{2}\right) \mathrm{NO}(\underline{9})-\underline{7}+\underline{1}+\frac{2-\mathrm{nY}-\mathrm{CMe}_{2} \mathrm{NO}_{2}}{-\mathrm{OP}}
\end{aligned}
$$

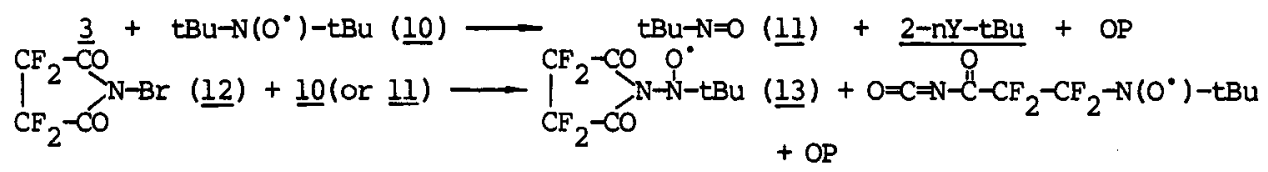

$$
\begin{aligned}
& \underline{4}+\text { donor }+\underline{11}-\underline{2-n Y-t B u}+O P \\
& \underline{3}+\mathrm{Ph}-\mathrm{NO}(\underline{15}) \quad \underline{2-\mathrm{nY}-\mathrm{Ph}}+\mathrm{OP} \\
& \mathrm{px}-\mathrm{C}_{6} \mathrm{H}_{4}-\mathrm{CF}^{-\mathrm{CF}_{2}}(\underline{16})+\mathrm{Br}_{2}+\underline{11}- \\
& \mathrm{PX}-\mathrm{C}_{6} \mathrm{H}_{4}-\mathrm{CF}\left(\mathrm{CF}_{2} \mathrm{Br}\right)-\mathrm{N}\left(0^{\circ}\right)-\mathrm{tBu}(\underline{17})+\mathrm{OP} \\
& \mathrm{R}+\mathrm{H}(\underline{18})+\underline{1}+\underline{7} \underline{\underline{2-n Y-R}+\mathrm{OP}}
\end{aligned}
$$

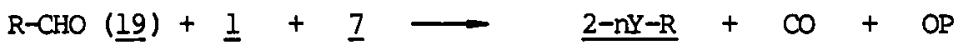

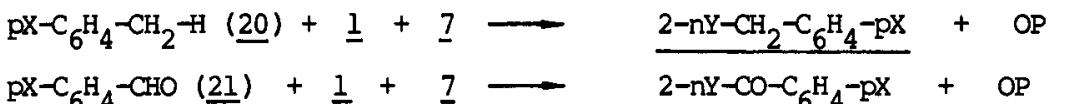

$$
\begin{aligned}
& \begin{aligned}
\mathrm{pX}-\mathrm{C}_{6} \mathrm{H}_{4}-\mathrm{CHO}(\underline{21})+\underline{1}+\underline{7}-\frac{2-\mathrm{nY}-\mathrm{CO}_{-} \mathrm{C}_{6} \mathrm{H}_{4}-\mathrm{pX}}{\underline{3}}+\mathrm{NO}-\mathrm{OP} \\
\underline{1}+\underline{7}+\mathrm{OP}
\end{aligned} \\
& \underline{3}+\mathrm{R}-\mathrm{NH}-\mathrm{R}(\underline{22}) \longrightarrow \mathrm{R}-\mathrm{N}\left(\mathrm{O}^{\circ}\right)-\mathrm{R}(\underline{23})+\mathrm{OP}
\end{aligned}
$$

In many of the above reactions, e.g., equations $1-5$ and 9-12, the spin trapping nitroso compounds 7 or 11 are formed during the course of reaction and then become precursors to the fluorinated nitroxides 1 or 2 . In other words, the $R_{F}{ }^{\prime}$ radicals derived from ETinitiated reactions are trapped by nitrosoalkanes generated in situ, thus leading to the formation of 1 or $\underline{2}$. Other nitrosoalkanes, e.g., 2-methyl-2-nitrosopropane (11) and nitrosobenzene $(\underline{15})$, have also been used to generate the fluorinated nitroxides $\underline{2}$ in reactions 6-8.

Many of the reactions have been studied at different temperatures in order to demonstrate the presence of the nitroso compounds (ref. 4, 10). For example, in reaction 6 , the blue colour of 2-methyl-2-nitrosopropane (11) is clearly observable at $-30^{\circ} \mathrm{C}$. When the temperature is raised to $0^{\circ} \mathrm{C}$, the blue color fades away while the ESR signals of the polyfluorinated nitroxides $\underline{2-n Y-t B u}$ become detectable.

The ratio of the nitroxide products $1 / \underline{2}$ in reaction 2 can be changed by changing the ratio of the reactants $\underline{3} / \underline{8}$. If an excess of the peroxides $\underline{3}$ is used, e.g., at molar ratio $\frac{3}{2} / \underline{8}=2: 1$, the radicals recorded will be mainly $1-n Y$ with a small amount of 2-nY-CRR'NO ${ }_{2}$. Presumably, under these conditions, relatively higher concentrations of $R_{T} \cdot$ radicals are formed and are easily traped by $R_{N} N(\underline{7})$. If a reversed ratio $(\underline{3} / \underline{8}=1: \underline{3})$ of the reactants is used, ESR signals of $2-\mathrm{nY}-\mathrm{CRR}_{\mathrm{RR}} \mathrm{N}_{2}$ become dominant (ref. 6).

Many new fluorinated nitroxides $2-n Y-R$ can also be generated by the hydrogen-atom abstraction reactions as shown in reactions $9-12$. When the very reactive radicals 1 make a protiumabstraction from alkanes $\mathrm{R}+\mathrm{H}(\underline{18}$ and $\underline{20})$ and aldehydes RCHO ( $\underline{19}$ and $\underline{21})$, the alkyl radicals $\mathrm{R}^{*}$ thus formed are immediately captured by $\frac{7}{7}$ and usually very stable fluorinated nitroxide products $2-n Y-R$ are recorded by ESR (ref. $1 \overline{1}, 15$ ). An interesting application of the fluorinated nitroxide chemistry is the elucidation of the mechanism of the bromination reaction of N-bromotetrafluorosuccinimide (12, see equation 5) (ref. 16). Although it is generally accepted that the bromination by $\mathrm{N}$-bromosuccinimide is a radical chain process (ref. 17), Martin (ref. 18) has suggested an ionic pathway for the bromination of electronrich olefins by 12 . Thus it would be of interest to see whether the imidyl radical derived from photolysis of 12 could be trapped by a nitroso compound such as $t$-Buno (see eq. 5 ). our results show that both the imidyl radical and its ring-opened radical product can be trapped to yield the ESR-identified radicals 13 and 14 . Furthermore, it has been shown that the bromination of 1-chloropentane by $\underline{12}$ also proceeds via radical pathways (ref.16).

Speculative mechanistic paths are proposed in Scheme 1. Equations 15-19 represent initiation steps of the reactions 1-13. Product studies accord with a mechanism which starts with an initial ET from the donor to the acceptor $(\underline{3}, \underline{4}$, or $\underline{5})$ and ends up with the formation of the key intermediate $R \cdot$ Some interesting mechanistic possibilities are suggested by equations 21-22, and by equation 23. The former depicts the fragmentation of a hypothetical intermediate 24, whereas the latter assumes a radical attack on an ambident ion. Equation 21-28 describe various pathways of the formation of another key intermediate, the nitroso compound $\mathrm{R}_{\mathrm{F}} \mathrm{NO}$. Equation 29 sumarizes the nitroxide formation steps. 


\section{Scheme 1}

A. ET, photo and thermal initiated reactions

$$
\begin{aligned}
& \left(\mathrm{R}_{\mathrm{F}} \mathrm{COO}\right)_{2}(\underline{3})+\text { donor } \mathrm{D} \rightarrow\left(\mathrm{R}_{\mathrm{F}} \mathrm{COO}\right)_{2}^{-}, \mathrm{D}^{+} \rightarrow \mathrm{R}_{\mathrm{F}}^{\cdot}+\mathrm{CO}_{2}+\mathrm{R}_{\mathrm{F}} \mathrm{COO} \mathrm{O}^{-}+\mathrm{OP} \\
& \mathrm{R}_{\mathrm{F}} \mathrm{I}(\underline{4})+\text { donor } \mathrm{D} \rightarrow \mathrm{R}_{\mathrm{F}} \mathrm{I}^{*}, \mathrm{D}^{+} \rightarrow \mathrm{R}_{\mathrm{F}}^{*}+\mathrm{I}^{-}+\mathrm{OP} \\
& \mathrm{R}_{\mathrm{F}} \mathrm{SO}_{2} \mathrm{Br}(\underline{5})+\text { donor } \mathrm{D} \rightarrow \mathrm{R}_{\mathrm{F}} \mathrm{SO}_{2} \mathrm{Br}^{-}, \mathrm{D}^{+} \rightarrow \mathrm{R}_{\mathrm{F}}^{+}+\mathrm{SO}_{2}+\mathrm{Br}^{-}+\mathrm{OP} \\
& 3 \stackrel{\Delta \text { or } \mathrm{ky}}{\longrightarrow} \mathrm{R}_{\mathrm{F}}^{\cdot}+\mathrm{CO}_{2} \\
& \underline{4} \stackrel{h u}{\longrightarrow} R_{F}^{\cdot}+I^{*}
\end{aligned}
$$

For illustration, if the donor is $\mathrm{RR}^{\prime} \mathrm{CNO}_{2} \mathrm{Na}(\underline{8})$, it can react with $\underline{3}$ according to equation 20.

$\underline{3}+\underline{8} \rightarrow\left(\mathrm{R}_{\mathrm{F}} \mathrm{COO}\right)_{2}{ }^{\top}, \mathrm{Na}^{+}, \mathrm{RR}^{\prime}\left(\mathrm{C}^{\cdot}\right) \mathrm{NO}_{2} \rightarrow \mathrm{R}_{\mathrm{F}} \mathrm{COOCRR} \mathrm{NO}_{2}(\underline{24})+\mathrm{R}_{\mathrm{F}}{ }^{\cdot}+\mathrm{OP}$

B. Formation of the $\mathrm{R}_{\mathrm{F}} \mathrm{NO}$ intermediate

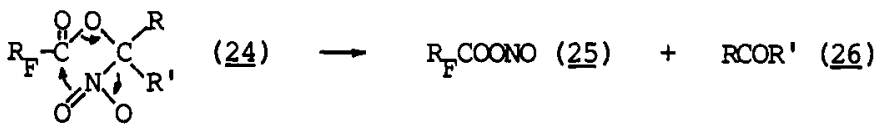

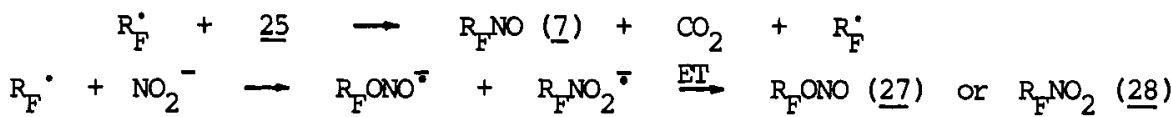

$$
\begin{aligned}
& 27 \stackrel{\text { various steps }}{2} \\
& 27-\mathrm{R}_{\mathrm{F}} \mathrm{O}^{\circ}+\mathrm{NO} \\
& \underline{27}+\mathrm{R}_{\mathrm{F}} \cdot \frac{1 \text { or } 2}{\text { steps }} \mathrm{R}_{\mathrm{F}} \mathrm{NO}(\underline{7})+\mathrm{R}_{\mathrm{F}} \mathrm{O}^{\circ}+\mathrm{OP} \\
& \mathrm{R}_{\mathrm{F}} \cdot+\mathrm{NO} \rightarrow \mathrm{R}_{\mathrm{F}} \mathrm{NO}(\underline{\mathrm{z}}) \\
& \mathrm{Me}_{2} \mathrm{C}\left(\mathrm{NO}_{2}\right) \mathrm{NO}+\mathrm{R}_{F}^{\cdot} \rightarrow \mathrm{R}_{\mathrm{FO}}(\underline{7})+\mathrm{OP}
\end{aligned}
$$

C. Spin-trapping reactions of $R_{F} N O$, or $R N O(R=t B u$ or $\mathrm{Ph})$

$R_{F}$ or $R^{\cdot}+R_{F} N(\underline{7})$ or $R N O(\underline{11}, \underline{14})-R_{F}-N\left(0^{\circ}\right)-R_{F}(\underline{1-n Y})$ or

$$
R_{\mathrm{F}}-\mathrm{N}\left(0^{\circ}\right)-\mathrm{R}(\underline{(2-n Y-R})
$$

\section{STRUCTURAL EFFECTS ON ESR PARAMETERS}

The presence of one or two polyfluoroalkyl groups in nitroxides $\underline{1}$ or $\underline{2}$ makes them interesting targets of ESR research, but the structural effects on ESR parameters of these nitroxides ( 1 and 2 ) have not been studied systematically. Ingold et al. (ref. 19) first used canonical structures $\mathrm{A}$ and $\mathrm{B}$ to rationalize the fact that the a value of $\mathrm{CF}_{3}-\mathrm{N}\left(\mathrm{O}^{\circ}\right)-\mathrm{CF}_{3}$ $\left(a_{1}=9.5 \mathrm{G}\right)$ is smaller than the $a$ values of $R-N\left(0^{\circ}\right)-R(a=c a .15 .3 G), R=N\left(O^{3}\right)-t-B u$ ( 11.1 to $12.3 \mathrm{G}$ ) and $\mathrm{R}_{\mathrm{F}}-\mathrm{N}\left(0^{\circ}\right) \mathrm{Ph}(9.5$ to $11.0 \mathrm{G}$ ) (ref. 3,28 ). In other words, the electronattracting groups will increase the relative importance of $\mathrm{A}$ and a smaller $\mathrm{q}_{\mathrm{N}}$ value will

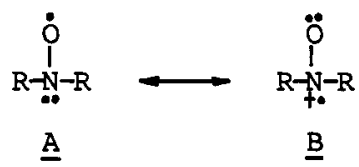

be expected. Table 1 reveals that the a values of perfluoroalkyl nitroxides $1-n F$ show a consistent trend (ref. 6,10 ). In other words, if the electron-attracting power of the $R_{\text {, }}$ groups are $\mathrm{CF}_{3}<\mathrm{C}_{2} \mathrm{~F}_{5}<\left(\mathrm{CF}_{3}\right)_{2} \mathrm{CF}<\left(\mathrm{CF}_{3}\right)_{3} \mathrm{C}$ (ref. 2l), then the decreasing order of an values $\left(\mathrm{CF}_{3}>\mathrm{C}_{2} \mathrm{~F}_{5}>\mathrm{n}^{-} \mathrm{C}_{3} \mathrm{~F}_{7}\right.$ and $\mathrm{n}-\mathrm{C}_{7} \mathrm{~F}_{15}$ ) nicely bears out the notion that in addition to gecmetric or conformational factors the polar effect may play a major role in affecting the $\mathrm{a}_{\mathrm{N}}$ values. 
Table I. ESR Parameters of ${ }^{14} \mathrm{~N}$ and ${ }^{15} \mathrm{~N}$-labelled Bis(polyfluoroalkyl) Nitroxides $1-n Y$ Generated in the Reactions of $\mathrm{NaNO}_{2}$ with Polyfluorodiacyl Peroxides 3 , Polyfluoroalkyl Idides $\underline{4}$ and Polyfluoroalkylsulfonyl Bromides 5 at $20 \pm 2^{\circ} \mathrm{C}$ (ref. 10 )

\begin{tabular}{|c|c|c|c|c|c|c|c|c|}
\hline $\mathrm{n}$ & $Y$ & $g$ & $\mathrm{a}_{\mathrm{N}}$ & $\frac{-1-n Y}{a^{\beta}}$ & $a_{F}^{r}$ & $a_{N}$ & $\frac{\frac{N-1-n Y}{a^{\beta}}}{\frac{1}{E}}$ & $a_{F}^{r}$ \\
\hline $\begin{array}{l}1 \\
2 \\
2 \\
2 \\
2 \\
4 \\
4 \\
6 \\
6 \\
6 \\
6\end{array}$ & $\begin{array}{r}\mathrm{F} \\
\mathrm{F} \\
\mathrm{Cl} \\
\mathrm{H} \\
\mathrm{CF}_{3} \\
\mathrm{Cl} \\
\mathrm{H} \\
\mathrm{Cl} \\
\mathrm{H} \\
\mathrm{CF}_{3} \\
\mathrm{CF}_{2} \mathrm{O}\end{array}$ & $\begin{array}{l}2.0069 \\
2.0071 \\
2.0069 \\
2.0068 \\
2.0070 \\
2.0071 \\
2.0071 \\
2.0072 \\
2.0071 \\
2.0072 \\
2.0071\end{array}$ & $\begin{array}{l}13.12 \\
12.13 \\
12.41 \\
13.62 \\
12.16 \\
12.47 \\
12.62 \\
12.45 \\
12.05 \\
12.38 \\
12.22\end{array}$ & $\begin{array}{r}8.28 \\
12.13 \\
10.87 \\
14.38 \\
9.96 \\
9.88 \\
9.98 \\
9.67 \\
9.81 \\
9.69 \\
10.22\end{array}$ & $\begin{array}{l}/ \\
1.03 \\
0.92 \\
/ \\
1.22 \\
1.19 \\
1.14 \\
1.15 \\
1.16 \\
1.12 \\
1.10\end{array}$ & $\begin{array}{l}9.35 \\
8.86 \\
8.65 \\
9.76 \\
8.80 \\
8.77 \\
8.94 \\
8.75 \\
8.61 \\
8.75 \\
8.54\end{array}$ & $\begin{array}{r}8.35 \\
12.13 \\
10.87 \\
14.40 \\
9.99 \\
9.77 \\
9.91 \\
9.67 \\
9.75 \\
9.74 \\
10.22\end{array}$ & $\begin{array}{l}/ \\
1.02 \\
0.89 \\
1 \\
1.20 \\
1.22 \\
1.44 \\
1.18 \\
1.16 \\
1.17 \\
1.10\end{array}$ \\
\hline
\end{tabular}

However, we should not take small differences in a values which might be caused by experimental uncertainties too seriously. In fact, the observed "a -orders" of the corresponding $14 \mathrm{~N}$ and $15 \mathrm{~N}$ spectra may not be identical. For instance, for the a values of the four $1-2 \mathrm{Y}$ nitroxides, the orders of their ${ }^{14} \mathrm{~N}$ and ${ }^{15} \mathrm{~N}$ spectra are $\mathrm{H}>\mathrm{F}>\mathrm{CF}_{3}>\mathrm{Cl}$ and $\mathrm{H}>\mathrm{Cl}_{3}>\mathrm{CF}_{3}>\mathrm{F}_{3}$ respectively. For the unsymetrical nitroxides 2-nY-tBu (ref. 14\%, the order $\mathrm{H}>\mathrm{CF}_{3}, \mathrm{Cl}^{3}>$ $F$ seems to parallel the trend in $\sigma_{x}$ and $\sigma_{I}$ values (ref. 22). Table II shows the ESR data of $\mathrm{H}\left(\mathrm{CF}_{2}\right)_{4}-\mathrm{N}\left(0^{\circ}\right)-\mathrm{R}(2-4 \mathrm{H}-\mathrm{R})$ with $\mathrm{R}$ groups of different sizes (ref. 11). Of particular interest is the trend in the $a_{H}$ values which decrease with the increasing bulk of the $R$ groups .

Table II. ESR Parameters of $\omega$-H-perfluorobutyl Alkyl Nitroxides (2-4H-R) Generated from Habstraction Reactions of Bis ( $\omega$-H-perfluorobutyl) Nitroxides $(\underline{1-4 H})$ and Alkanes $\mathrm{R}-\mathrm{H}(\underline{18})$. in Fll3, $20 \pm 2^{\circ} \mathrm{C}$

\begin{tabular}{cccccc}
\hline $\mathrm{R}-\mathrm{H}$ & $\mathrm{g}$ & $\mathrm{a}_{\mathrm{F}}^{\beta}$ & $\mathrm{a}_{\mathrm{E}}^{\gamma}$ & $\mathrm{a}_{\mathrm{H}}$ \\
\hline $\mathrm{PhCH}_{2} \mathrm{H}$ & 2.0062 & 10.67 & 15.73 & 1.65 & 6.79 \\
$\mathrm{PhMeCH}+\mathrm{H}$ & 2.0062 & 11.17 & 15.88 & 1.68 & 3.98 \\
$\mathrm{PhEtCH}+\mathrm{H}$ & 2.0062 & 11.01 & 17.97 & 1.45 & 3.53 \\
$\mathrm{Ph}_{2} \mathrm{CH}-\mathrm{H}$ & 2.0062 & 10.92 & 16.28 & 1.34 & 2.96 \\
$\mathrm{Fl}-\mathrm{H}$ & 2.0063 & 10.60 & 17.99 & 1.04 & 2.02 \\
$\mathrm{PhMe}_{2} \mathrm{C}+\mathrm{H}$ & 2.0061 & 11.74 & 14.75 & 0.89 & \\
$\mathrm{EtMe}_{2} \mathrm{C}-\mathrm{H}$ & & 11.75 & 20.89 & & \\
\hline
\end{tabular}

a. $\mathrm{Fl}=$ 9-Fluorenyl.

${ }^{15} \mathrm{~N}$ labelled nitroxides 1 and 2 as well as nitroso compounds $\mathrm{R}_{\mathrm{p}} \mathrm{NO}$ ( 7 ), have been generated by reactions of $\mathrm{Na}^{15} \mathrm{NO}_{2}$ with $3, \underline{4}$, and $\underline{5}$ in $\mathrm{CF}_{2} \mathrm{ClCFCl}_{2}$ (Fll3) at $20^{\circ} \mathrm{C}$ (ref. 10). Typical ESR spectra are illustrated by Fig. 1 and 2 . Certainly, the simpler splittings and larger a values of these ${ }^{15} \mathrm{~N}$ labelled nitroxides can be quite helpful in studing radical reactions, e.g., H-abstractions from alkanes $\mathrm{R}-\mathrm{H}$ (18) (ref. 1l).

\section{SUBSTITUENT EFFECTS ON ESR PARAMETERS $a_{N}$ AND $a_{F}$ OF FLUORINATED NITROXIDES}

In radical chemistry, when steric effects are negligible, substitutent effects on structure and reactivity are usually discussed in terms of two factors, i.e., polar and spin-delocalization effects (ref. 23). The former includes both inductive/field and resonance effects, and is usually related to Hanmet type parameters $\sigma^{x}, e . g ., \sigma_{p}, \sigma^{+}, \sigma_{I}, \sigma_{R}, \sigma_{m b}, \ldots$ etc, whereas the latter, hopefully, should be represented by a spin-delocalization parameter, $\sigma^{\circ}$ (ref. 23).

In the past decade, we have been trying to set up a reliable $\sigma^{*}$ scale $\left(\sigma_{j J}^{*}\right)$ as well as a polar $\sigma_{m b}$ scale for systems with a substituent on an aryl ring that conjugates with a multiple bond (mb) (ref. 23, ). This review reports some preliminary results of correlation analysis of substituent parameters $\left(\sigma^{x}\right.$ and $\left.\sigma^{\circ}\right)$ with ESR parameters $\left(a_{N}\right.$ and $\left.a_{F}\right)$ of nine 

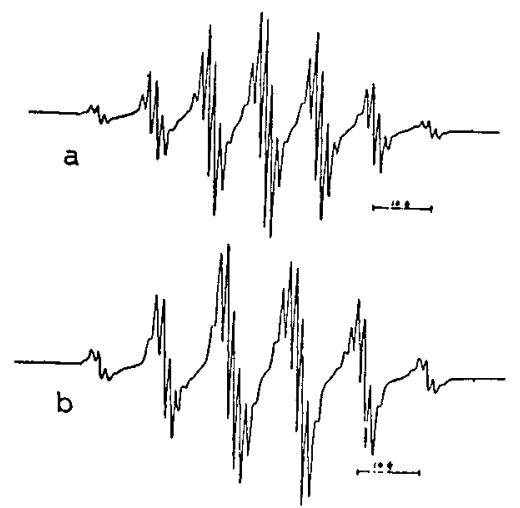

Fig.1, ESR spectra of $\mathrm{nC}_{3} \mathrm{~F}_{7} \mathrm{~N}\left(0^{\circ}\right)$ $\mathrm{nC}_{3} \mathrm{~F}_{7}$ formed from $\left(\mathrm{C}_{3} \mathrm{~F}_{7} \mathrm{COO}\right)_{2}$ and $\mathrm{Na}^{14} \mathrm{NO}_{2}$ (spectrum a) or $\mathrm{Na}{ }^{15} \mathrm{NO}_{2}$ (spectrum b) in Fll3.
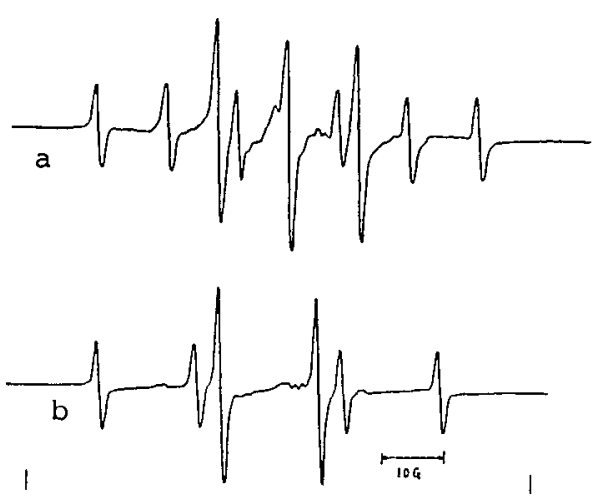

Fig,2. ESR spectra of $\mathrm{nC}_{3} \mathrm{~F}_{2} \mathrm{~N}\left(\mathrm{O}^{\circ}\right)$ tam formed from $\left(\mathrm{C}_{3} \mathrm{~F}_{7} \mathrm{COO}_{2}\right)_{2}$, isopentane and $\mathrm{Na}^{14} \mathrm{NO}_{2}^{3}$ (spectrum a) or $\mathrm{Na}^{13} \mathrm{NO}_{2}$ (spectrum b) in $\mathrm{F} 113$.

para-substituted benzoyl polyfluoroalkyl nitroxides $2-6 \mathrm{H}-\mathrm{CO}-\mathrm{C}_{6} \mathrm{H}-\mathrm{pX}(\mathrm{X}=\mathrm{MeO}, \mathrm{Et}, \mathrm{Me}, \mathrm{H}$, $\mathrm{F}, \mathrm{Cl}, \mathrm{Br}, \mathrm{CF}_{3}, \mathrm{NO}_{2}$; $\mathrm{Cf}$. eq. 12; ref. 12 ). As expected (vide supra), electron-attracting

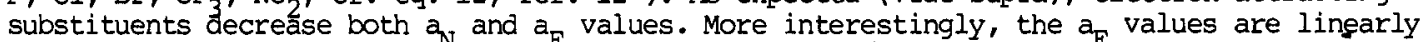
related to $\sigma_{p}(r=0.991, \mathrm{~F}=399.2 \mathrm{~F}, \mathrm{n}=9, \mathrm{~s}=0.053, \psi=0.050)$, and a two-parameter equation with $\sigma_{p}$ and $\sigma_{j J}^{\circ}(r=0.999, F=648.6, n=6, s=0.021, \psi=0.039)$ does not seem to improve the correlation. This result suggests that the canonical structure $E$ is of no importance (ref. 12).

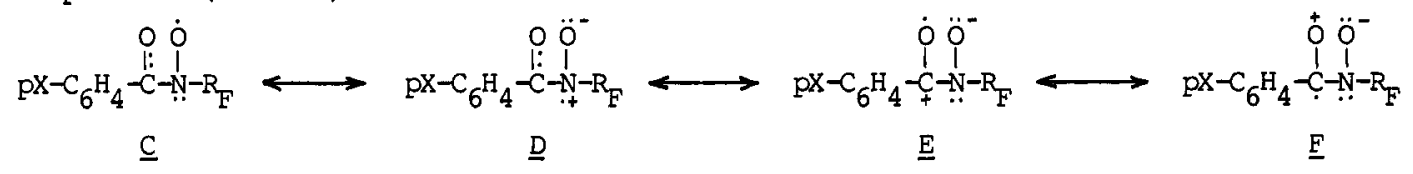

\section{THE TEMPERATURE DEPENDENCE OF THE SPLITTING CONSTANTS OF FLUORINATED NITROXIDES}

Apparently, not too much systematic work has been done on the dependence of a values on temperature. We have measured a values for nitroxides in the temperature range of +20 to $-120^{\circ} \mathrm{C}$, and found that they slowly decrease with decreasing temperature (ref. 15). Variable-temperature studies of nitroxides in solution by ESR spectroscopy have shown selective line broadening in some fluorinated nitroxides. This was attributed to restricted rotation of the $\alpha-\mathrm{N}-\mathrm{C}$ bonds at low temperatures by Ingold (ref. 25 ) and Tabata (ref. 3 ). For instance, the fact that the three fluorine atoms in $\mathrm{CF}_{3} \mathrm{~N}\left(\mathrm{O}^{\circ}\right) \mathrm{OtBu}^{\circ}(\mathrm{cf}$. G) become

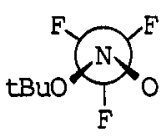

$\underline{G}$<smiles>[R]N1O[CH][C@H](F)[R]1F</smiles>

븐

nonequivalent at low temperatures indicates that rotation of the $\mathrm{CF}_{3}$ around the $\alpha-\mathrm{N}-\mathrm{C}$ bond has been frozen (ref. 25).

Notably, we have observed three types of behavior of the nitroxides 2-nY-R, i.e., (1) those which do not clearly show line broadenig, e.g., 2-3F-tBu, etc. (ref. 15), (2) those which show broadening of the center lines (as shown in ref. 3,25 ), e.g., $2-2 F-R$, with $\underline{R}=t B u, t-$ $\mathrm{Am}$, etc. (ref.13, 15), and (3) those which show broadening of the side lines, e.g., 2-3F-tAm, etc. (ref. 13). The third behavior does not seem to have been previously observed. Evidently, subtle interactions which affect ESR of these nitroxides are at present still not fully understood. As an illustration of the complexity of this problem, we might mention that intramolecular hydrogen-bonding may affect the conformer population distribution of nitroxides with hydrogen on the $\beta$-carbon, i.e., 2-2H-R (cf. structrue $H$ and ref. 10, 11 ).

\section{REFERENCES}

1, H. G. Aurich in The Chemistry of Amino, Nitroso and Nitro Compounds and Their Derivatives, S. Patai, Ed., pp. 565-622, Wiley, New York (1982) ; E. G. Rozantsev and V. D.Sholle, Synth. Pp. 191, 401 (1971) E. G. Janzen, Acc. Chem. Res., 2, 279, (1969); R. E. Banks, 
R. N. Haszeldine and M. J. Stevensen, J. Chen. Soc., 901 (1966); B. L. Booth, D. J. Edge, R. N. Haszeldine and R. G. G. Holmes, J. Chem. Soc., Perkin 2 , 7 (1977); V. Malatesta and K. U. Ingold, J. Am. Chem. Soc., $10 \overline{03}, 3958$ (1981); T. Doba and K. U. Ingold, J. Am. Chem. Soc., 106, 3958 (1984).

2. S. P. Makarov, A. Y. Yakubovich, S. S. Dubov and A. N. Medvedev, Doklady Akad. Nauk SSSR, 160,1319 ( 1965); W. D. Blackley and R. R. Reinhard, J. Am. Chen. Soc., 87, 802, (1965).

3. Gasanov R. G, Kandror I. I., Khorlina M. Ya and Freidlina R. Kh, Izv. Akad. Nauk SSSR, Ser. Khim 1758 (1976); Y. Katsumura, K. Ishigure and Y. Tabata, J. Phys. Chem., 833152 (1979) : K. J. Klabunde, J. Am. Chem. Soc., 92, 2427, (1970).

4. Ginsburg, V.A., Medvedev A.N., Dubov S.S, Gitel P.O., Smolyanitskaya V.V. and Nikolaenko G. E, Zh. Obshch. Khim. 39282 (1969) and references cited therein; J.D. Crabtree, R.N. Haszeldine, A.J. Parker, K. Ridings, R.F. Simmons and S. Smith, J. Chem. soc. Perkin 2, 111 (1972); Leslie H.Sutcliffe and Anna Zilynk, J. Chem. Soc. Faraday Trans. I, 81, 679 (1985).

5, Cheng-Xue Zhao, Guo-Fei Chen, Xian-Shan Wang and Xi-Kui Jiang, J. Fluorine Chem. 31, 417 (1986).

6. Cheng-Xue Zhao, Xi-Kui Jiang, Guo-Fei Chen, Yan-Ling Qu, Xian-Shan Wang and Jian-Ying Lu, J. Am. Chem. Soc., 108, 3132 (1986).

7. Cheng-Xue Zhao, Guo-Fei Chen, Xi-Kui Jiang and Xian-Shan Wang, J. Fluorine Chem. 35, 597 (1987).

8. Cheng-Xue Zhao, Guo-Fei Chen, Yan-Ling Qu and Xi-Kui Jiang, J. Fluorine Chem. 37, 215 (1987).

9. Cheng-Xue Zhao, Guo-Fei Chen, Xi-Kui Jiang and Xian-Shan Wang, J. Chem. Soc., Chem. Camun., 1362 (1986).

10. Cheng-Xue Zhao, Guo-Fei Chen and Xi-Kui Jiang, J. Fluorine Chem., 38, 391 (1988).

11. Guo-Fei Chen, Yu-Je Hu, Yan-Ling Qu, Cheng-Xue Zhao and Xi-Kui Jiang, Acta Chimica Sinica, accepted.

12. Cheng-Xue Zhao, Guo-Fei Chen and Xi-Kui Jiang, Abstracts of Papers, The 3rd National Conference on Physical Organic Chenistry, p. 130, Suzhou, China, Oct. 16-21, 1987.

13. Cheng-Xue Zhao, Guo-Fei Chen and Xi-Kui Jiang, to be published; Cheng-Xue zhao, XianShan Wang, Jian-Ying Lu, Guo-Fei Chen and Xi-Kui Jiang, unpublshed results.

14. Yu-Huang Zhang, Guo-Fei Chen, Cheng-Xue Zhao and Xi-Kui Jiang, to be published; YuHuang Zhang, Guo-Fei Chen and Xi-Kui Jiang, to be published; Yu-fluang Zhang, Guo-Fei Chen, Guo-Zhen Ji and Xi-Kui Jiang, unpublshed results.

15. Guo-Fei Chen, Yu-Huang Zhang and Xi-Kui Jiang, to be publshed; Guo-Fei Chen, ChengXue Zhao and Xi-Kui Jiang, unpublished results.

16. Yu-Huang Zhang, Guo-Fei Chen, Cheng-Xue Zhao, Ming-Hua Dong, Yuan-Lang Chow and XiKui Jiang, to be published; Yu-tluang Zhang, Ming-Hua Dong, Xi-Kui Jiang and Yuan L. Chow, submitted for publication.

17. Yuan L. Chow and Da-Chuan Zhao, J. Org. Chem. 52, 1931 (1987)

18, J. H. Incremona and J. C. Martin, J. Am. Chem. Soc. 92, 627 (1970)

19, C . Chatglilaloglu, V. Malatesta and K. U. Ingold, J. Phys. Chem., 84, 3597 (1980).

20. G. R. Underwood, V. L. Vogel and Ira Krefting, J. Am. Chem. Soc., 92, 5019 (1970); E. G. Janzen, B. R. Knauer, J. L. Gerlock and K. J. Klabunde, J. phys. Chem., 74, 2037 (1970); S. Terabe and R. Konaka, Bull. Chem. Soc. Japan, 46, 825 (1973); C. Chatgilialoglu and K. U. Ingold, J. Am. Chem. Soc., 103, 4833 (1981).

21. Ching-Yun Chen, Xi-Kui Jiang, Bing-Qi Chen and Meng-Lan Liang, Scienta Sinica, 15, 498 (1966); L. M. Yagopolskii A. Y. Ilchenko and N. V. Kondratenko, Russ. Chem. Rev, ' 43,32 (1974); N. Naji and P. Moreau, J. Fluorine Chem., 38, 19 (1988).

22. S. Ehrenson, R. T. C. Brownlee and R. W. Taft, in Progress in Physical Organic Chemistry, A. S. Streitwieser, JR and R. W. Taft, Eds., vol. 10, p. 13, Wiley, New York (1973); R. W. Taft and R. D. Topson, in Progress in Physical Organic Chemistry, R. W. Taft, Ed., vol. 16, p. 16, Wiley, New York (1987).

23, Xi-Kui Jiang, Guo-Zhen Ji and Chong-Xi Yu, Acta Chimica Sinica, 42, 599 (1984);Eng. Ed. 82 (1984) and references cited therein; Guo-Zhen Ji, Xi-Kui Jiang, Yu-Huang Zhang, Yi-Qun Shi and Xiu-Lian Zhang, Abstracts of Papers, 9th IUPAC conference on Physical Organic Chemistry, p. 124, Regenshurg, August 21-26, 1988; Guo-zhen Ji, Yu-tuang Zhang, Yi-Quan Shi, Xiu-Lian Zhang, Bing-Quan Li, Shan-Gang Yuan and XiKui Jiang, Abstracts of Papers, Kyushu Symposium on Physical Organic Chemistry, p. 140, Fukuoka, Oct. 7-11, 1988; X. Creary, M. E. Mehrsheikh-Mohammadi and S. McDonald, J. Org. Chem. 523254 (1987); D. R. Arnold, NATO ASI Ser., Ser. C 189 171 (1986); R. Merenyi, Z. Janousekh. H. G. Viehe, in Substituent Effects in Radical Chemistry, H. G. Viehe, Ed., pp. 301-324, D. Reidel Publishing Co., Dordrecht (1986).

24, P. J. Scheidler and J. R. Bolton, J. Am. Chem. Soc. 88,371 (1966).

25. C. Chatgilialoglu and K. U. Ingold, Can. J. Chem., 59, 1745 (1981); C. Chatgilialoglu and K. U. Ingold, J. Phys. Chem. 86, 4372 (1982).

Acknowledgement I wish to thank the National Natural Science Foundation of China for financial support. 